\title{
Concurrent Bell's palsy and diabetes mellitus: a diabetic mononeuropathy?
}

\author{
P PECKET, A SCHATTNER* \\ From the Neurological Unit and Department of Medicine $C,{ }^{*}$ Kaplan Hospital, Rehovot, affiliated to the \\ Hebrew University \& Hadassah Medical School, Jerusalem, Israel
}

SUMMARY In a series of 126 patients with Bell's palsy, chemical or overt diabetes mellitus was found in $39 \%$ of the cases. A high frequency of disturbances of taste was found in the patients who had no diabetes $(83 \%)$, as compared to only $14 \%$ of diabetic patients whose taste was affected $(p<0.001)$. Thus, the usual site of facial nerve lesion in diabetics appears to be distal to the chorda tympani, while in patients whose glucose tolerance is normal, no such selectivity exists. This may only be explained by a diabetes-related pathogenesis and a vascular rather than a generalised "metabolic" impairment is postulated, leading to a localised facial nerve ischaemia in the distal part of the Fallopian canal. Thus, some cases of Bell's palsy may in fact be a diabetic mononeuropathy.

Since Korczyn first reported a high frequency of diabetes mellitus in patients presenting with Bell's palsy, ${ }^{1}$ this association has been confirmed by others, ${ }^{23}$ so that screening for diabetes mellitus was recommended for patients presenting with this neurological deficit. Conversely, the risk of Bell's palsy is increased in diabetes. ${ }^{2}$ It was also noted that diabetic patients with Bell's palsy were much more prone to develop a more severe nerve injury and had a less favourable outcome. ${ }^{45}$ A suggestion was made that Bell's palsy resulted from ischaemia of the facial nerve, due in many cases to diabetic small vessel disease, ${ }^{1}$ but no convincing evidence for a causal relation was presented so far. Bell's palsy is prominent among the causes of taste impairment, but the reported frequency of taste involvement in Bell's palsy varies. ${ }^{67}$ Taste has not yet been studied in concurrent diabetes mellitus and Bell's palsy, and may perhaps be used to clarify the dilemma of this relationship. ${ }^{4}$

\section{Patients and methods}

One hundred and eighty-four consecutive patients were referred for treatment of Bell's palsy, during a period of

Address for reprint requests: Dr A Schattner, Kaplan Hospital, POBI, Rehovot, Israel.

Received 23 January 1982

Accepted 16 February 1982 five years. Fifty-eight cases had to be excluded from the study, either because more than five days had elapsed between the onset of the symptoms and presentation, or because investigations had not been completed. The remaining 126 patients had a fasting blood-glucose determination and levels above $130 \mathrm{mg} / \mathrm{dl}$ on two separate occasions were considered to be diabetic. In each of the other patients, an oral glucose tolerance test was performed, and interpreted according to Fajans and Conn. ${ }^{8}$ When whole blood glucose level had not fallen below $120 \mathrm{mg} / \mathrm{dl}$, two hours after the oral glucose load-the diagnosis of chemical diabetes was made. (In patients over 50 years old, 10 $\mathrm{mg} / \mathrm{dl}$ per decade were added to the post-glucose values.) Taste impairment was detected by inquiring for a loss or alteration of sensation, and by testing with salt and sugar solutions on each side of the tongue. In doubtful cases (taste disturbances established by only one of the methods), electrogustometry was performed; only those with an abnormal result ( $>10 \mu \mathrm{A}$ threshold difference) were considered to be suffering from an impairment of taste. All evaluations of taste were performed by the same observer (PP) when the patient first presented. Glucose determination and glucose tolerance tests were performed later, but within 24 hours of presentation and prior to the initiation of prednisone treatment.

\section{Results}

Out of the 126 patients examined, 13 were known diabetics and only two further cases were diagnosed on presentation as having overt diabetes mellitus. In another 34 cases, an abnormal glucose tolerance test 
result was found, thus the overall frequency of diabetes in this series of Bell's palsy was $39 \%$ (table). Chemical diabetes mellitus is evidently more prevalent than overt diabetes among the patients with Bell's palsy, in a ratio of $2 \cdot 2: 1$. Of the patients with overt diabetes mellitus, seven patients had diabetes of less than one year duration, and of these none required insulin treatment. No other clinical evidence of diabetic neuropathy was found in these patients on presentation. However, five patients (out of 49) were again referred to us owing to the development of other neurological symptoms, and the diagnosis of diabetic mononeuropathy (three occulomotor palsies, one trochlear nerve, one femoral nerve) was established, more than a year following the Bell's palsy. Taste disturbances were detected in 71 patients $(56.3 \%)$. Their incidence in patients with Bell's palsy and diabetes mellitus was lower than in the patients whose glucose tolerance test was normal (table). Of the 77 patients with normal glucose tolerance, $64(83 \%)$ had impairment of taste, while the incidence in the diabetes group was only $14 \%(p<0.001)$. No differences of age or sex were found between the groups presented in the table.

\section{Discussion}

Thirty-nine per cent of the 126 patients with Bell's palsy evaluated by us had diabetes mellitus, a high frequency which is in agreement with previously published data. ${ }^{1-4}$ An overall frequency of $56.3 \%$ of taste disturbances was found in our series, while other authors, using various assessment methods, report a similar frequency of about $60 \% .^{7910}$ However, in the sub-group of diabetic patients, a considerably lower frequency of taste impairment was found. Only $14 \%$ of diabetics had taste involvement as compared to $83 \%$ of patients with a normal glu- cose tolerance. This difference is suggestive of a pathogenesis which is directly related to the diabetes, in most of the cases of concurrent diabetes mellitus and Bell's palsy. The sparing of taste in most of these cases is analogous to the sparing of pupillary fibres in third nerve lesions due to diabetes but not to other causes, ${ }^{11-13}$ and likewise may have an anatomical explanation. The chorda tympani carrying taste fibres from the anterior two thirds of the tongue, joins the facial nerve in its bony canal 5-6 mm above the stylomastoid foramen. ${ }^{14}$ To spare taste, nerve lesion in diabetics with Bell's palsy would have to be located distal to the bifurcation of the chorda tympani. In the rest of the cases where another aetiology, possibly viral, is involved, ${ }^{1516}$ we found no evidence of such a localised lesion and the facial nerve seems to be affected throughout or mainly proximal to the chorda tympani, involving taste as well as motor function. Pathological studies of diabetes with a recent Bell's palsy are unavailable, so the nature of the facial nerve lesion and the reasons for the special vulnerability of the distal part of the facial nerve in diabetes, cannot be ascertained. However, it seems that no generalised metabolic abnormality in the Schwann cell and myelin sheath of diabetics ${ }^{17} 18$ can account for such a selective lesion, while a vascular pathogenesis is more probable.

The relationship of small vessel disease in diabetes to neuropathy ${ }^{19} 20$ and mononeuropathy in particular ${ }^{1821-23}$ has been reported and related to nerve ischaemia in infarcts. This was confirmed by several pathological studies ${ }^{1124-26}$ and by the similarity to the mononeuropathy of polyarteritis nodosa, in which nerve infarcts have also been demonstrated. ${ }^{27}$ The blood supply of the facial nerve in the petrous bone comes from two main sources: ${ }^{28-31}$ the stylomastoid artery (originating from the occipital or posterior-auricular arteries and ascending through

Table Type and duration of diabetes and frequency of taste impairment among patients with Bell's palsy

\begin{tabular}{|c|c|c|c|c|}
\hline Diagnosis & No of patients & $\%$ & \multicolumn{2}{|c|}{ Duration of diabetes } \\
\hline Overt & 15 & 12 & $\begin{array}{l}\text { newly discovered } \\
<1 \mathrm{yr} \\
>1 \mathrm{yr}\end{array}$ & $\begin{array}{l}2 \mathrm{pts} \\
5 \mathrm{pts} \\
8 \mathrm{pts}\end{array}$ \\
\hline $\begin{array}{l}\text { Chemical } \\
\text { No diabetes }\end{array}$ & $\begin{array}{l}34 \\
77\end{array}$ & $\begin{array}{l}27 \\
61\end{array}$ & - & \\
\hline Total & 126 & 100 & & \\
\hline Diagnosis & Taste impairment ${ }^{*}$ & Taste unaffected & Total & \\
\hline $\begin{array}{l}\text { No diabetes } \\
\text { Diabetes }\end{array}$ & $\begin{array}{r}64(83 \%) \\
7(14 \%)\end{array}$ & $\begin{array}{l}13(17 \%) \\
42(86 \%)\end{array}$ & $\begin{array}{l}77 \\
49\end{array}$ & \\
\hline Total & 71 pts & 55 pts & 126 & \\
\hline
\end{tabular}

${ }^{*} \mathrm{~A} \chi^{2}$ test for independence in $2 \times 2$ contingency table was performed. The $\chi^{2}$ statistic $=57.67$, is highly significant in 0.001 level (p<0.001). 
the stylomastoid foramen), and the branches of the petrosal artery (originating from the middle meningeal artery, entering the hiatus Fallopii and descending in the bony canal). Ample anastomosis exist between them, ${ }^{28-31}$ however, this does not preclude the possibility of diabetic small vessel disease affecting the blood supply of the distal part of the facial nerve, possibly at the loop formed by the stylomastoid artery on entering the skull,,$^{29}$ or at its bifurcation at an acute angle to form the chorda tympani branch. ${ }^{29}{ }^{30}$ Indeed, embolisation of both arteries was followed by a clinical picture very similar to Bell's palsy. ${ }^{32}{ }^{33}$ It may be argued that a highly susceptible area of the microcirculation often occurs distal to the chorda tympani, hence diabetic small vessel disease may cause localised facial nerve ischaemia (infarction?) and oedema, which would further compromise the nerve's blood supply due to the rigid Fallopian canal at that area. ${ }^{1}$ In that respect, the facial nerve shows marked similarity to the other nerves commonly affected by diabetic mononeuropathy: ${ }^{22}$ all traverse an enclosed space which makes them especially vulnerable to the effects of ischaemia. ${ }^{34}$ The clinical profile of Bell's palsy, with sudden, painful asymmetrical onset and the pattern of gradual recovery, also is suggestive of nerve ischaemia and similar to a diabetic mononeuropathy, ${ }^{23}$ although most of the cases have a different aetiology, and nerve oedema and ischaemia are probably secondary phenomena. ${ }^{32} 3536$ Our findings as to the severity and duration of diabetes mellitus in our patients (table) are in agreement with the known data that diabetic mononeuropathies tend to occur in mild diabetes of short duration and to be independent of other types of diabetic neuropathy. ${ }^{22}{ }^{37}$ Subclinical involvement of the controlateral side and other cranial nerves in Bell's palsy ${ }^{3839}$ cannot be interpreted as indicative only of an infective aetiology, ${ }^{15}$ as it is also found in diabetes mellitus,$^{40}$ even with newly diagnosed disease. ${ }^{4142}$ The reported occurrence of Bell's palsy with other diabetic cranial neuropathies ${ }^{4344}$ further supports a possible causal association between diabetes mellitus and Bell's palsy. In one report, $25 \%$ of patients with diabetic ophthalmoplegia had a past history of Bell's palsy. ${ }^{13}$ We therefore propose that the sparing of taste fibres in cases with concurrent diabetes mellitus and Bell's palsy may be related to diabetic small vessel disease, and that these cases of Bell's palsy may in fact be regarded as a diabetic mononeuropathy.

\section{References}

' Korczyn AD. Bell's palsy and diabetes mellitus. Lancet 1971;1:108-10.

${ }^{2}$ Adour KK, Wingerd J, Doty HE. Prevalence of concur- rent diabetes mellitus and idiopathic facial paralysis (Bell's Palsy). Diabetes 1975;24:449-51.

${ }^{3}$ Lundgren A, Adkvist LM, Hendriksson KG, Lavsson LE, Karlberg BE, Jervall L. Facial palsy in diabetes mellitus-not only a mononeuropathy? $A d v$ Otorhinolaryngol 1977;22:182-9.

${ }^{4}$ Adour KK, Bell DN, Wingerd J. Bell's palsy. Dilemma of diabetes mellitus. Arch Otolaryngol 1974;99:114 7.

${ }^{5}$ Adour KK, Wingerd J. Idiopathic facial paralysis (Bell's palsy): Factors affecting severity and outcome in 446 patients. Neurology (Minneap) 1974;24:1112-6.

${ }^{6}$ May M, Hardin WB. Facial palsy: interpretation of neurologic findings. Laryngoscope 1978;88:1352-62.

${ }^{7}$ Groves J, Gibson WPR. Significance of taste and electrogustometry in assessing the prognosis of Bell's (idiopathic) facial palsy. J Laryngol Otol 1974; 88:855-61.

${ }^{8}$ Fajans SS, Conn JW. Early recognition of diabetes mellitus. Ann NY Acad Sci 1959;82:208-18.

${ }^{9}$ May M, Hardin WB, Sullivan J, Wette R. Natural history of Bell's palsy: the salivary flow test and other prognostic indicators. Laryngoscope 1976;86:704-12.

${ }^{10}$ May M, Schlaepfer WW. Bell's palsy and the chorda tympani nerve: a clinical and electron microscopic study. Laryngoscope 1975;85:1957-75.

${ }^{1}$ Dreyfus PM, Hakim S, Adams RD. Diabetic ophthalmoplegia. Arch Neurol Psychiat 1957;77:337-49.

${ }^{12}$ Rucker CW. Paralysis of the third, fourth and sixth cranial nerves. Am J Ophth 1958;46:787-94.

${ }^{13}$ Goldstein JE, Cogan DG. Diabetic ophthalmoplegia with special reference to the pupil. Arch Ophth 1960;64:592-600.

${ }^{14}$ Kudo H, Nori S. Topography of the facial nerve in the human temporal bone. Acta Anat 1974;90:467-80.

${ }^{15}$ Adour KK. Cranial polyneuritis and Bell's palsy. Arch Otolaryngol 1976;102:262-4.

${ }^{16}$ Adour KK, Byl FM, Hilsinger RL, Kahn ZM, Sheldon MI. The true nature of Bell's palsy: analysis of 1000 consecutive patients. Laryngoscope 1978;88:787801 .

${ }^{17}$ Thomas PK, Lascelles RG. The pathology of diabetic neuropathy. QJ Med 1966;35:489-509.

${ }^{18}$ Winegrad AI. Diabetic neuropathy (editorial). $N$ Engl J Med 1972;286:1261-2.

${ }^{19}$ Fagerberg SE. Diabetic neuropathy: a clinical and histological study on the significance of vascular affections. Acta Med Scand 1959;164 (supp 345): 1-80.

${ }^{20}$ Goldenberg S, Alex M, Joshi RA, Blumenthal HT. Nonatheromatous peripheral vascular disease of the lower extremity in diabetes mellitus. Diabetes 1959;8:261-73.

${ }^{21}$ Locke S. The nervous system in diabetes. In: Marble A, White P, Bradley RF, Krall LP, eds. Joslin's diabetes mellitus. Philadelphia; Lea and Febiger, 1971.

${ }^{22}$ Fraser DM, Campbell IW, Ewing DJ, Clarke BF. Mononeuropathy in diabetes mellitus. Diabetes 1979; 28:96-101.

${ }^{23}$ Spritz N. Nerve disease in diabetes mellitus. Med Clin N Am 1978;62:787-98.

${ }^{24}$ Raff MC, Sangalang V, Asbury AK. Ischaemic mononeuropathy multiplex associated with diabetes mel- 
litus. Arch Neurol 1968;18:487-99.

${ }^{25}$ Skanse B, Gydell K. A rare type of femoral-sciatic neuropathy in diabetes mellitus. Acta Med Scand 1956;155:463-8.

${ }^{26}$ Ellenberg M, Krainer L. Diabetic neuropathy: review of literature and a case report with post-mortem findings. Diabetes 1959;8:279-83.

${ }^{27}$ Lovshin LL, Kernohan JW. Peripheral neuritis in periarteritis nodosa: a clinicopathologic study. Arch Intern Med 1948;82:321-38.

${ }^{28}$ Blunt MJ. The blood supply of the facial nerve. J Anat 1954;88:520-6.

${ }^{29}$ Clarke JA. An X-ray microscopic study of the arterial supply to the facial nerve. J Laryngol Otol 1965;79:987-94.

${ }^{30}$ Lasjaunias P, Moret J. Normal and non-pathological variations in the angiographic aspects of the arteries of the middle ear. Neuroradiology 1978;15:213-9.

${ }^{31}$ Lasjaunias P, Moret J, Doyon D, Vignaud J. Exploration arteriographique du nerf facial intra-petreux: embryologie et aspect radio-anatomique normaux. Neuroradiology 1978;16:246-8.

${ }^{32}$ Calcaterra TC, Rand RW, Bentson JR. Ischemic paralysis of the facial nerve: a possible etiologic factor in Bell's palsy. Laryngoscope 1976;86:92-7.

${ }^{33}$ Moret J, Lasjaunias P, Doyon D, Vignaud J. Etude angiographique des paralysies faciales. Neuroradiology 1978;16:308-10.

34 Richards RL. Ischaemic lesions of peripheral nerves: a review. J Neurol Neurosurg Psychiatry 1951;14:7680.
${ }^{35}$ McGovern FH. A review of the experimental aspects of Bell's palsy. Laryngoscope 1968;78:324-32.

${ }^{36}$ Anson BJ, Warpeha RL, Donaldson JA et al. The facial nerve, sheath and blood supply in relation to the surgery of decompression. Ann Otol Rhinol Laryngol 1970;79:710-27.

${ }^{37}$ Massey EW, O'Brian JT. Mononeuropathy in diabetes mellitus-a phenomenon easily overlooked. Postgrad Med 1979;65:129-38.

${ }^{38}$ Safman BL. Bilateral pathology in Bell's palsy. Arch Otolaryngol 1971; 93:55-7.

${ }^{39}$ Chaco J. Subclinical peripheral nerve involvement in unilateral Bell's palsy. Am J Phys Med 1973;52:1957.

40 Johnson EW, Waylonis GW. Facial nerve conduction delay in patients with diabetes mellitus. Arch Phys Med Rehabil 1964;45:131-9.

${ }^{41}$ Ward JD, Barnes CG, Fisher DJ, Jessop JD, Baker RWR. Improvement in nerve conduction following treatment in newly diagnosed diabetics. Lancet 1971;1:428-31.

${ }^{42}$ Faerman I, Fox D, Zadzinsky MN, Glocer L, Cibeira JB. Neurological findings in chemical diabetes. In: Camerini-Dávalos RA, Cole HS, eds. Vascular and neurological changes in early diabetes. New York: Academic Press, 1973:451.

${ }^{43}$ Ross AT. Recurrent cranial nerve palsies in diabetes mellitus. Neurology (Minneap) 1962;12:180-5.

${ }^{44}$ Larson DL, Auchincloss JH. Multiple symmetric bilateral cranial nerve palsies in patients with unregulated diabetes mellitus. Arch Intern Med 1950;85:265-71. 